\title{
Analysis of Photodegradation Products of Organic Photochromes by LC/MS
}

\author{
Young-Hee Lim, Yeu Young Youn, Kyung Hoon Kim, and Hye-Sung Cho* \\ LG Chem.Ltd./Research Park, 104-1 Moonji-dong, Yuseong-gu, Daejeon 305-380, Korea \\ Received September 13, 2012; Revised December 21, 2012; Accepted December 24, 2012 \\ First published on the web December 27, 2012; DOI: 10.5478/MSL.2012.3.4.101
}

\begin{abstract}
The ultraviolet (UV) degradation products of photochromic naphthoxazine and naphthopyran derivatives in acetonitrile were separated and identified using liquid chromatography-mass spectrometry (LC-MS). Photodegradation resulted in oxidation of products.
\end{abstract}

Key words: UV degradation, Naphthoxazine, Naphthopyran, LC-MS

\section{Introduction}

Two well-known photochromic compounds, naphthoxazines and naphthopyrans, exhibit a thermally reversible color change, both in solution and when sequestered in a polymer matrix, when exposed to ultraviolet (UV) radiation. ${ }^{1}$ Upon exposure to UV radiation, these compounds are converted from colorless, close-ring states to colored, openring states. $^{2-7}$

Prolonged exposure to UV radiation and oxygen tends to degrade photochromic dyes, leading to losses in photochromism. ${ }^{8,9}$ This lack of durability has limited the commercial applicability of most photochromic dyes. Typical photooxidation products result from ring-opening reactions. Some hypotheses involve the reaction of molecular oxygen with diradical species created during the opening of a C-O bond. This reaction mechanism has been suggested by Malatesta et al. ${ }^{9}$ in a series of naphthoxazines. The present study examines the photodegradation of two common photochromic compounds (I) and (II) (Tabel 1 and 2) as a function of UV exposure time. Proposed structures of the photodegradation products were based on LC-MS and LC-MS/MS data.

\section{Experimental}

\section{Materials}

All solvents were HPLC-grade and purchased from J.T. Baker (Phillipsburg, NJ, USA). Water was deionized with a Milli-Q water purification system (Millipore, Billerica, MA, USA). 6'-(2,3-Dihydro-1H-indol-1-yl)-1,3-dihydro-3,3dimethyl-1-(2-methylpropyl)-

spiro[2H-indole-2,3'-[3H]naphth[2,1-b][1,4]oxazine] and

\footnotetext{
*Reprint requests to Dr. Hye-Sung Cho
}

E-mail: hschoc@lgchem.com
4-[4-[6-(4-morpholinyl)-3-phenyl-3H-naphtho[2,1-b]pyran-3 -yl]phenyl]-morpholine were obtained from LG Chem's Research Park facility.

\section{Chromatographic separation}

Chromatographic separation was performed using a Hewlett-Packard HPLC system (HP1100; Palo Alto, CA, USA). The HPLC column was a Capcellpak $(4.6 \mathrm{~mm}$ ID $\times 50 \mathrm{~mm} \mathrm{~L}, 5 \mu \mathrm{m}$, hexadecyl-bonded silica; Shiseido, Tokyo, Japan). Components I and II of the mobile phase were deionized water and acetonitrile, respectively. Mobile phase solvents were filtered and degassed through a $0.45 \mu \mathrm{m}$ membrane filter. A gradient elution was used, starting with a linear increase from $20 \%$ to $100 \%$ component II over $10 \mathrm{~min}$. The mobile phase composition was then maintained at $100 \%$ component II for $15 \mathrm{~min}$. The flow rate was $1.0 \mathrm{~mL} / \mathrm{min}$ and a UV detector monitored the eluate absorbance at $254 \mathrm{~nm}$.

\section{Mass spectrometry}

Mass spectrometric analyses were performed on a LCQ (Finnigan, MAT, USA) and LTQ Orbitrap Elite (Thermo, Bremen, Germany) equipped with an atmospheric pressure chemical ionization (APCI) interface. Mass spectrometric parameters for the LCQ for APCI were as follows: vaporizer temperature $350^{\circ} \mathrm{C}$, sheath gas flow rate $80 \mathrm{~L} / \mathrm{h}$, auxiliary gas flow $10 \mathrm{~L} / \mathrm{h}$, capillary temperature $150^{\circ} \mathrm{C}$, tube lens offset $46 \mathrm{~V}$, scan range $\mathrm{m} / z$ 50-1200 Da, and collision energy $30 \%$. The parameters of Orbitrap were as follows: vaporizer temperature $450^{\circ} \mathrm{C}$, sheath gas flow rate $50 \mathrm{~L} / \mathrm{h}$, auxiliary gas flow $5 \mathrm{~L} / \mathrm{h}$, capillary temperature $275^{\circ} \mathrm{C}$, S-Lens RF level of $50 \%$, and scan range $\mathrm{m} / \mathrm{z} 10$ $1000 \mathrm{Da}$. The mass analyzer was used in positive ion mode.

\section{Sample preparation}

Photochromic solutions were prepared by dissolving compounds (I) or (II) in acetonitrile to approximately 10 
mM. Photodegradation was performed with a UV condensation weathering device (ATLAS UV2000, $0.77 \mathrm{~W} / \mathrm{m}^{2}$ at $340 \mathrm{~nm}$ ). Eight solutions were prepared with various UV exposure times $(0 \mathrm{hr}, 4 \mathrm{hr}, 27 \mathrm{hr}, 40 \mathrm{hr}, 59 \mathrm{hr}$, $86 \mathrm{hr}, 117 \mathrm{hr}$, and $241 \mathrm{hr}$ ).

\section{Results and Discussion}

Both of the photochromic compounds studied herein underwent significant UV-induced photodegradation in acetonitrile. The peak corresponding to compound (I) completely disappeared after $86 \mathrm{hr}$ of UV exposure. The primary degradation product, evident in all of the compound (I) solutions, was eluted at $6.2 \mathrm{~min}$. Table 1 gives mass data for the various degradation products, including proposed elemental compositions and mass deviations (difference between theoretical and measured mass). High-accuracy masses were obtained with the Orbitrap mass spectrometer. Based on these data, the photodegradation product responsible for the LC peak at $6.2 \mathrm{~min}$ was likely 3,3-dimethyl-1-(2-methylpropyl) oxindole. The photoproducts eluted at 10.1 and $10.3 \mathrm{~min}$

Table 1. Retention times (RT), observed masses, elemental compositions, mass deviations and expected structure of degradation products of compound (I).

\begin{tabular}{|c|c|c|c|c|}
\hline $\begin{array}{l}\text { RT } \\
(\mathrm{min})\end{array}$ & $\begin{array}{c}\text { Observed } \\
\operatorname{mass}(m / z)\end{array}$ & $\begin{array}{c}\text { Expected } \\
\text { elemental } \\
\text { composition }\end{array}$ & $\begin{array}{c}\text { Mass } \\
\text { deviation } \\
(\mathrm{ppm})\end{array}$ & $\begin{array}{l}\text { Expected } \\
\text { Structure }\end{array}$ \\
\hline 4.7 & 276.10141 & $\mathrm{C}_{18} \mathrm{H}_{14} \mathrm{NO}_{2}$ & -1.794 & \\
\hline 6.2 & 218.15382 & $\mathrm{C}_{14} \mathrm{H}_{20} \mathrm{NO}$ & -0.554 & \\
\hline 10.1 & 511.24835 & $\mathrm{C}_{34} \mathrm{H}_{31} \mathrm{~N}_{4} \mathrm{O}$ & -1.737 & \\
\hline 10.3 & 513.26392 & $\mathrm{C}_{34} \mathrm{H}_{33} \mathrm{~N}_{4} \mathrm{O}$ & -1.886 & \\
\hline 10.5 & 486.25308 & $\mathrm{C}_{33} \mathrm{H}_{32} \mathrm{~N}_{3} \mathrm{O}$ & -1.870 & \\
\hline 10.7 & 488.26886 & $\mathrm{C}_{33} \mathrm{H}_{34} \mathrm{~N}_{3} \mathrm{O}$ & -1.596 & \\
\hline & & & & Compoun \\
\hline
\end{tabular}

were likely naphthoxazole compounds that had reacted with cyanide ions donated by acetonitrile. Table 1 also shows proposed structures of the degradation products eluted at 4.7, 6.2, 10.1, 10.3, and $10.5 \mathrm{~min}$. The structures are based on accurate masses and the fragment ions generated in MS/MS mode. Figure 1 shows the fragmentation pattern obtained from the compound eluted at $10.5 \mathrm{~min}$. Almost all of the proposed degradation products are analogs of the photoproducts of the

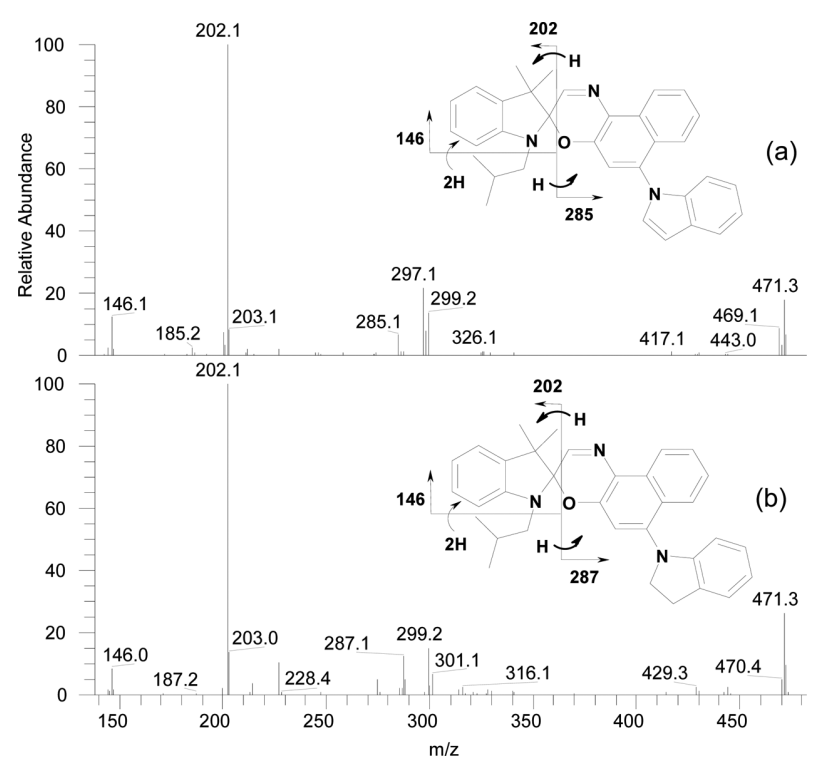

Figure 1. MS/MS spectra of (a) the degradation product of compound (I) eluted at $10.5 \mathrm{~min}$ and (b) compound (I).

Table 2. Retention times (RT), observed masses, elemental compositions, mass deviations and expected structure of degradation products of compound (II).

\begin{tabular}{ccccc}
\hline $\begin{array}{c}\text { RT } \\
(\mathrm{min})\end{array}$ & $\begin{array}{c}\text { Observed } \\
\text { mass }(\mathrm{m} / \mathrm{z})\end{array}$ & $\begin{array}{c}\text { Expected } \\
\text { elemental } \\
\text { composition }\end{array}$ & $\begin{array}{c}\text { Mass } \\
\text { deviation } \\
(\mathrm{ppm})\end{array}$ & $\begin{array}{c}\text { Expected } \\
\text { Structure }\end{array}$ \\
\hline 4.3 & 298.10703 & $\mathrm{C}_{17} \mathrm{H}_{16} \mathrm{NO}_{4}$ & -1.189 \\
5.3 & 268.13281 & $\mathrm{C}_{17} \mathrm{H}_{18} \mathrm{NO}_{2}$ & -1.474 \\
7.4 & 535.22241 & $\mathrm{C}_{33} \mathrm{H}_{31} \mathrm{~N}_{2} \mathrm{O}_{5}$ & -0.633 \\
& & & & \\
8.5 & 505.24805 & $\mathrm{C}_{33} \mathrm{H}_{33} \mathrm{~N}_{2} \mathrm{O}_{3}$ & -1.028 \\
& & & &
\end{tabular}




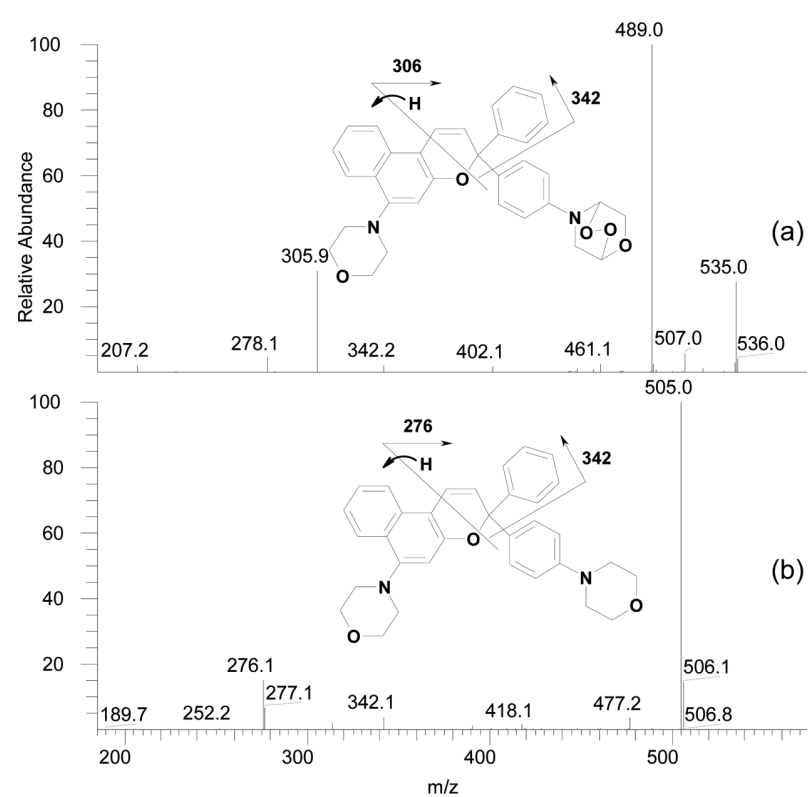

Figure 2. MS/MS spectra of (a) the degradation product of compound (II) eluted at 7.4 min and (b) compound (II).

unsubstituted compound (I). This confirms that degradation occurred by the reaction of oxygen with the open-ring form of compound (I).

Compound (II) showed no significant signs of degradation until after $59 \mathrm{hr}$ of exposure. Non-degraded compound (II) was evident even after $241 \mathrm{hr}$ of exposure. Table 2 shows accurate masses and proposed structures of the degradation products of compound (II). Based on fragment ions generated in MS/MS mode, the degradation products were likely morpholinyl benzophenone, formed from the open-ring form of the initial naphthopyran, and morpholine endoperoxide compounds. Figure 2 shows the fragmentation pattern of the compound eluted at $7.4 \mathrm{~min}$.

\section{Conclusions}

UV degradation of naphthopyran and naphthoxazine compounds yields oxidized products in acetonitrile. The main products of photodegradation of the naphthoxazine compound were analogues of the same unsubstituted compound. Photodegradation of the naphthopyran compound yielded benzophonone derivatives. Thus, the photooxidation mechanism of these photochromic dyes involves the reaction of oxygen with their open-ring forms. The naphthopyran compound was more resistant to photodegradation than the naphthoxazine compound.

\section{References}

1. Baillet, G. Mol. Cryst. Liq.Cryst.1997, 298, 75.

2. Malatesta, V. Mol. Cryst. Liq.Cryst. 1997, 298, 69.

3. Aramaki, S.; Atkinson, G. H. Chem. Phys. Lett. 1990, $170,181$.

4. Tamai, N.; Masuhara, H. Chem. Phys. Lett. 1992, 191, 189.

5. Salemi-Delvaux, C.; Baillet. G.; Giusti. G.; Guglielmetti, R. J. Photochem. Photobiol. A 1995, 91, 223.

6. Pimienta, V.; Froute, C.; Deniel, M. H.; Lavabre, D.; Guglielmetti, R.; Micheau, J. C. J. Photochem. Photobiol. A 1999, 122, 199.

7. Kumar, A. Mol. Cryst. Liq.Cryst. 1997, 298, 139.

8. Salemi-Delvaux, C.; Campredon, G.; Guglielmetti, R. Mol. Cryst. Liq.Cryst. 1997, 298, 61.

9. Milosa, M.; Malatesta, V.; Millini, R.; Lanzini, L.; Bortolus, P.; Monti, S. Mol. Cryst. Liq.Cryst. 1994, 246, 303. 